\title{
ESTAÇÃO FERROVIÁRIA - A BELA ADORMECIDA DE SANTO ANASTÁCIO - SP
}

Bruna Melina Mariano Tebar, Bruno Oliveira Lopes, lane Baltazar Aguilar, Juliana Elaine dos Santos, Eliana Nunes Ribeiro

Universidade do Oeste Paulista - UNOESTE. Curso de Arquitetura e Urbanismo, Presidente Prudente - SP. E-mail: elianaribeiro@unoeste.br

\section{RESUMO}

$\mathrm{O}$ artigo em questão tem como seu objetivo realizar o estudo e o levantamento histórico e arquitetônico da estação ferroviária na cidade de Santo Anastácio no qual gerou um inventario arquitetônico. O edifício tem uma grande importância histórica para a região, pelo fato de a edificação fazer parte de um conjunto de prédios pertencentes à estrada de ferro Sorocabana, a qual foi instaurada na região antes inabitada, trazendo desenvolvimento político e econômico as cidades por onde passava. A partir do estudo desenvolvido e considerando a importância das estações para a região do Oeste Paulista, foram detectado patologias na edificação, dados históricos, métricos e fotográficos.

Palavras-chave: Estação Ferroviária, Patrimônio histórico e cultural, Santo Anastácio, Sorocabana, Oeste Paulista.

\section{RAILWAY STATION - A SLEEPING BEAUTY OF SANTO ANASTÁCIO - SP}

\section{ABSTRACT}

The article in question has as its objective to make the study and the historical and architectural survey of the railway station in the city of St. Anastasius in which generated an architectural inventory. The building has great historical significance for the region, because the building part of a complex of buildings belonging to the railroad Sorocabana, which was brought before the uninhabited region, bringing political and economic development of the cities where he stopped. From the study developed and considering the significance of the stations for the western region of São Paulo, pathologies in the building, historical, metric and photographic data were detected.

Keywords: Railway Station, historic and cultural heritage, Santo Anastacio, Sorocabana Oeste Paulista. 


\section{INTRODUÇÃO}

O presente artigo reúne dados e informações históricas sobre as condições da estação ferroviária de Santo Anastácio-SP, busca-se ressaltar de certa maneira a importância histórica e cultural do edifício para a cidade e região.

Segundo web site oficial da Prefeitura Municipal de Santo Anastácio, a cidade é localizada na região oeste paulista, à aproximadamente $550 \mathrm{~km}$ da capital, consta ainda que no começo do século era uma região inexplorada, habitada por tribos indígenas e cercada por matas.

Até 1905 a estrada de ferro sorocabana pertencia a empresários liderados por comerciantes de algodão, foi então transferida ao governo do estado de São Paulo, pelo crescente interesse na criação de uma ligação da capital com o Mato Grosso, propôs o alongamento da estrada de ferro Sorocabana, que até então ligava São Paulo a cidade de Assis-SP (JUNIOR,1995).

O citado projeto previa a continuidade da linha férrea até Porto Tibiriçá (atual cidade Presidente Epitácio-SP), passando pelo povoado Vai e Vem, hoje cidade de Santo Anastácio - SP, criando então a comissão de prolongamento e desenvolvimentos, tendo como engenheiro chefe o Dro Joaquim Huet de Bacellar e o Dro João Carlos Fairbanks como engenheiro de campo. Em 1920, o Dro Silvano Wendel auxiliado por um agrimensor executa o planejamento para tornar o povoado conhecido como Vai e Vem em cidade, tendo como uma de suas características marcantes as ruas e avenidas mais largas que a de qualquer outra cidade da região. (JUNIOR, 1995).

Segundo web site da prefeitura Municipal de Santo Anastácio, o desenvolvimento da região chamou atenção dos grandes latifundiários que detinham terras, onde firmaram parceria com o objetivo de lotear e comercializar as glebas rurais para povoação. Em 1921 a cidade foi elevada a categoria de distrito da cidade de Presidente Prudente, até que em 1925 conseguiu autonomia política.

De acordo com as pesquisas realizadas o prédio da estação ferroviária pertencente ao território de Santo Anastácio faz parte de um conjunto de edifícios que eram utilizados para embarque e desembarque de cargas e passageiros da Estrada de Ferro Sorocabana instaurada no final da década de 20 .

O estado atual da estação é de deterioração causada pelas a intemperes, e a falta de manutenção. Devido às más condições do edifício este trabalho tem como objetivo a realização de um Inventário do patrimônio histórico ferroviário da Estação da cidade de Santo Anastácio - SP, a fim de verificar seu potencial histórico cultural, para colaborá-la com as pesquisas na cidade e região. 
Dessa maneira realizaram-se levantamentos históricos sobre a Estrada de Ferro Sorocabana e as Estações Ferroviárias, relacionando-as com a expansão do Oeste Paulista, que remontam ao século XIX, e também verificar e avaliar o estado de conservação das edificações - estação, pátio, habitações e seu entorno.

\section{METODOLOGIA}

Para a estruturação deste artigo foi necessário realizar um levantamento bibliográfico buscando o aprofundamento acerca dos temas relacionados à pesquisa, tais como: história da ferrovia no estado de São Paulo e na região do oeste paulista; patrimônio histórico, turístico cultural e ferroviário, tais materiais foram levantados junto a biblioteca municipal, museu municipal e demais órgãos que disponibilizaram acervo histórico, foram realizados levantamentos métricos, levantamentos fotográficos in loco.

Foram coletadas informações sobre a história da cidade de Santo Anastácio - SP e sua relação com o povoamento da região do Oeste Paulista, além de dados sobre a construção da estação.

\section{UM POUCO DA HISTÓRIA}

A estação ferroviária de santo Anastácio pertence ao um conjunto de edificações que fazem parte da malha férrea da estrada de ferro sorocabana, que interliga a capital do estado ao interior (figura1).

O atual edifício da estação ferroviária de Santo Anastácio está localizado próximo ao centro comercial da cidade, na Rua Dom Pedro II, s/n, teve sua construção iniciada em 1938 e concluída em 1940. A estação foi um pedido feito por parte de diversos nomes da cidade, os quais achavam que era digno e necessário substituir a estação que ali existia, um casebre de madeira. Em abril de 1935, foi enviado um manifesto redigido pelo jornal local "O Oeste Paulista", com assinaturas de representantes de diferentes classes, ao diretor da estrada de ferro Sorocabana, Dro A. Prudente de Morais, para a implantação do novo edifício, o mesmo que recusou o pedido, deixando os cidadãos descontentes, por não justificar o porquê de tal decisão já que a cidade arrecadou grandes quantias para à Sorocabana nos anos anteriores (Jornal, O Oeste Paulista, Santo Anastácio, 29/agosto/1937). 


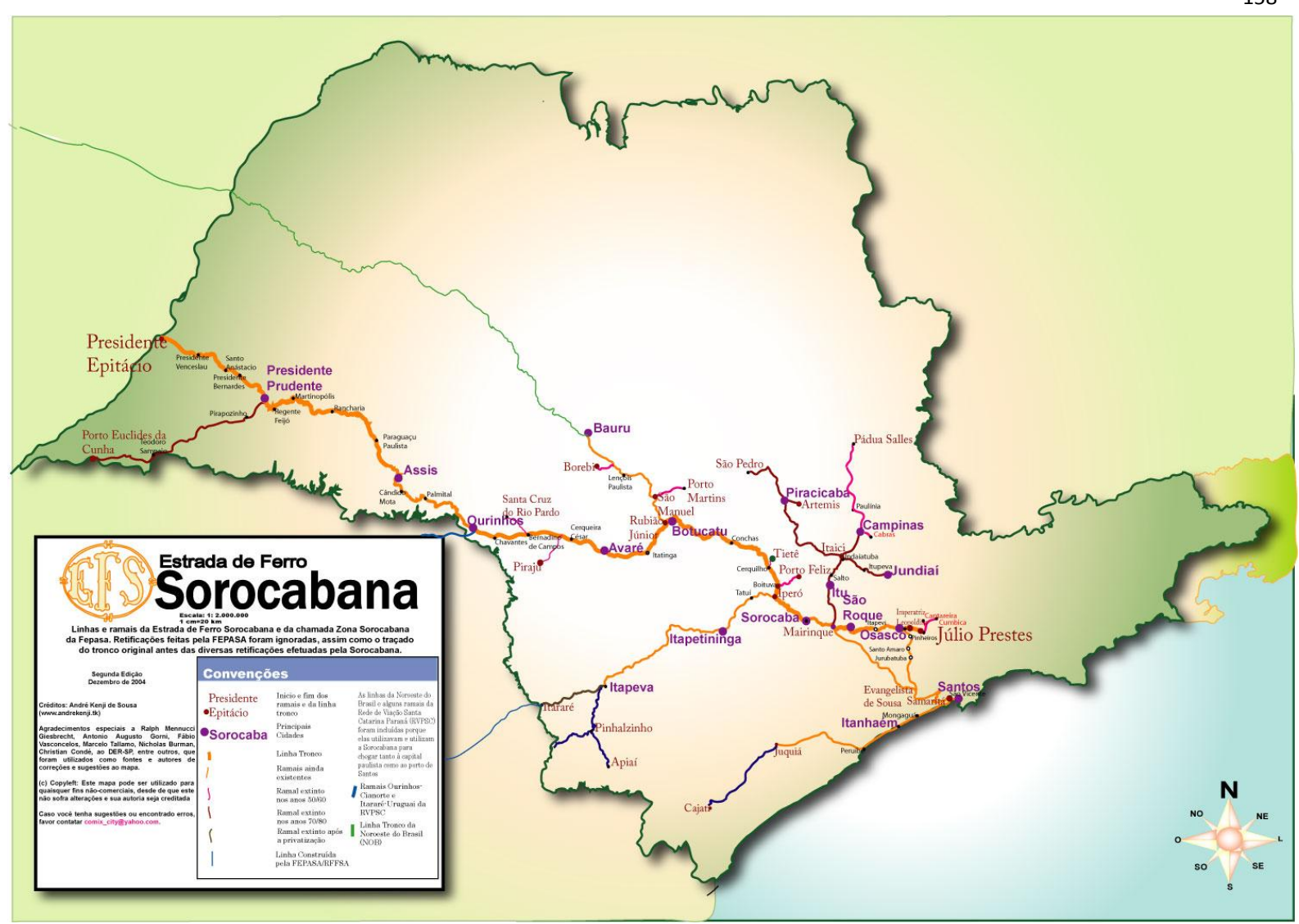

Figura 1. linhas férreas da sorocabana.

FONTE: site www.saopaulotremjeito.blogspot.com.br

Em março de 1936 depois de mudada a direção da estrada sorocabana, foi decretada a construção em caráter de urgência da estação no município de Santo Anastácio, tal ordem dada pelo então atual diretor Dro Mario Sales Solto. Foi dito que seriam feitos estudos no local para a construção da nova estação, e durante todo o ano de 1936 nada foi feito, então o diretor foi novamente pressionado. Em agosto de 1937 foram iniciados os estudos preparatórios para a edificação do novo prédio. O próprio diretor da estrada de ferro foi in loco com outros estudiosos tirar medidas e fazer analise do local. Foi então decretado que a companhia da estrada de ferro sorocabana iria dispor de mais de 300 mil contos de reis para a construção da nova estação, a qual o manifesto fazia exigência do valor de 150 mil contos de reis. (Jornal, O Oeste Paulista, Santo Anastácio, 27/julho/1937). A figura a seguir mostra a foto tirada no dia de sua inauguração. 


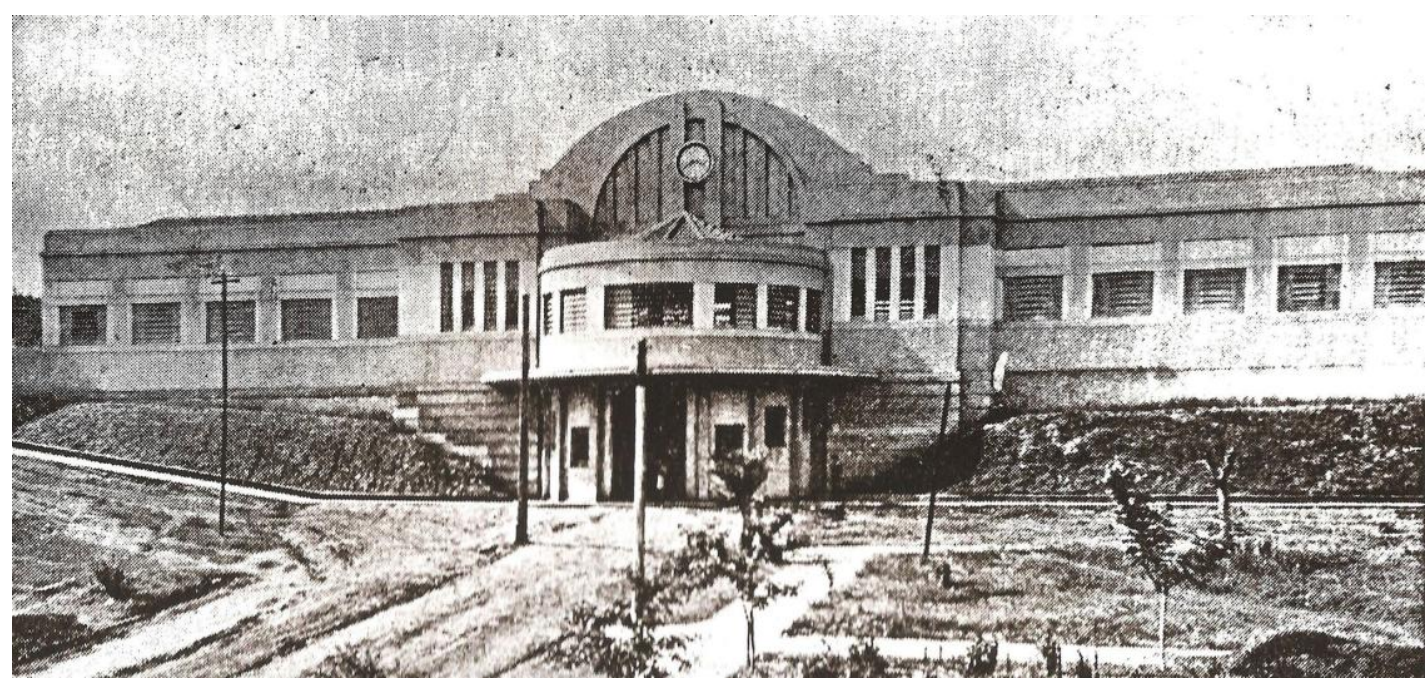

Figura 2. Estação ferroviária no dia da inauguração.

Fonte: Museu Municipal - acervo de data não informada.

As estações que ainda existem ganharam um novo uso ou estão em estado de abandono, de maneira a se degradarem com o passar do tempo sem que aja uma preocupação com o símbolo e significado as quais esses monumentos trazem da historia e do desenvolvimento de suas cidades. Devido a sua grande relevância e importância histórica para o desenvolvimento da região a edificação conserva em si traços da historia o que a atribui importância como "patrimônio histórico cultural de um povo ou nação".

Segundo LEMOS (1987), existem duas vertentes para a definição de patrimônio: com bens físicos, objetos, artefatos, e edificações obtidas através de materiais moldados com as técnicas do saber as quais fazem parte da segunda categoria os quais são chamados de bens não tangíveis, os quais são adquiridos com o passar do tempo, os dois grupos juntos formando uma identidade cultural.

\section{O ESTILO ART DÉCO}

O Art Déco é um estilo arquitetônico, que se consolidou na década de 1940, chegando tardio na arquitetura brasileira. Um estilo muito conhecido no mundo, no fim da década de 1920 e inicio da década de 1930. O art déco tem origem na Exposition Internacionale des Arts Décoratifs e Industriels, em Paris, 1925, o estilo caracteriza-se pelo o uso de materiais luxuosos, motivos estilizados e linhas dinâmicas, ritmo das fachadas, e racionalização, sendo utilizados em arranhacéus e cinemas, um dos seus maiores exemplos foi o Edifício Empire States, Nova York, EUA (GLANCEY, 2000).

No Brasil a arquitetura Art Déco, foi muito utilizada em prédios institucionais, pois representava progressismo administrativo e modernidade. 


\section{CARACTERÍSTICAS RELEVANTES DA ESTAÇÃO}

O estilo Art Déco se caracteriza na estação por sua forma regular e aerodinâmica totalmente preservada, pois desde sua construção nunca passou por grandes reformas. A planta consiste basicamente em um retângulo, é interessante ressaltar que não há corredores isto quer dizer que as salas são interligadas umas ás outras, sendo que todas possuem portas que saem para o pátio de embarque.

A entrada principal se dá por um volume cilíndrico localizado no centro da planta, com escadarias que leva o público até o saguão. Saindo do saguão para o pátio de concreto temos grandes pilares cilíndricos que sustentam uma cobertura plana, ao lado temos um volume retangular onde anteriormente era usado como manutenção e armazenamento de maquinários, hoje é utilizado por uma oficina de serralheria, o resto da estação foi utilizado por um tempo como biblioteca e museu, mas devido seu estado de conservação foi fechada permanecendo sem uso.

Assim como o pátio toda a construção é de concreto, com portas e janelas de ferro, foro de madeira, piso de granilite, e paredes externas revestidas de ladrilhos, todos esses materiais acompanham o estilo da época. Na figura baixo, mostra em planta baixa a estação.
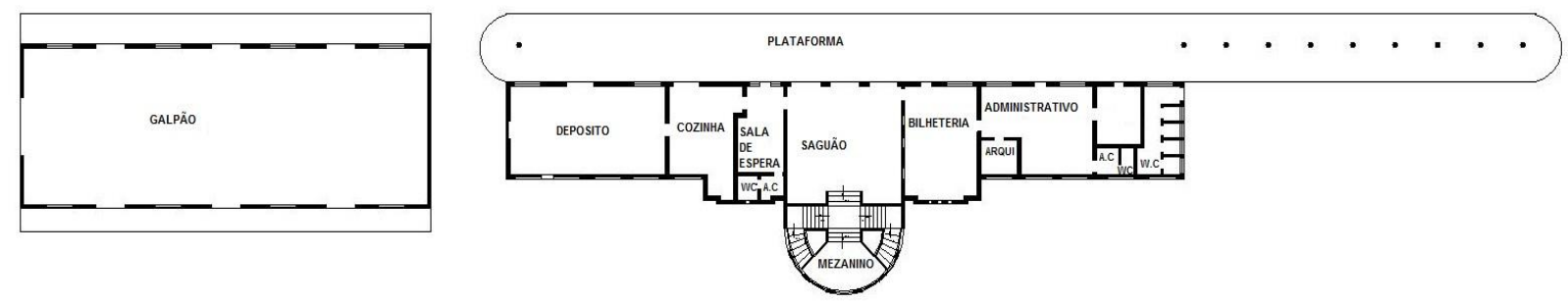

Figura 3. Planta Baixa da estação.

Fonte: do Autor.

As estações ferroviárias tiveram um papel muito importante no país, seu crescimento prolongamento levou desenvolvimento para uma região esquecida, eram o meio de comunicação e transporte mais usado na época, com estilos arquitetônicos diferentes, algumas muito suntuosas e outras de modelo mais simples. Normalmente eram edificações diferenciadas e monumentais, as quais se encontram hoje na sua maioria abandonadas, se mantém em uso ainda as estações metropolitanas, algumas outras com uso turístico e algumas poucas ainda de uso para cargas pelas atuais concessionárias das ferrovias. 


\section{ANALISES DAS CONDIÇÕES ATUAIS}

Desde a sua inauguração em 1940 não houve nenhuma reforma geral na estação, apenas pequenos reparos, isto na época em que a ferrovia funcionava até meados da década de 90 . edifício ficou vários anos fechado após a desativação da FEPASA, por volta de 2007 a prefeitura local passou a utilizar o edifício como museu municipal, como o local não tinha sofrido nenhuma reforma começaram a apresentar patologias, a partir deste momento a estação foi fechada para a reforma.

Na entrada principal do edifício, pelas escadarias, alguns degraus estão com o revestimento de granilite quebrado. O forro do mezanino está se soltando, nas salas administrativas o mesmo já não existe, totalmente caído e com o telhado aparente, em ambos os forros são de madeira. O piso de taco que reveste as salas administrativas, bilheteria e o depósito, estão com tacos faltando, mostrando o contrapiso. As paredes e a laje do saguão e alguns ambientes apresentam rachaduras, mofos, descascamento da pintura. Algumas janelas estão quebradas, e inclusive as janelas da bilheteria. Alguns ladrilhos que revestem vários ambientes estão amarelos com a ação do tempo, quebrados, alguns caíram no período em que a estação era utilizada e o azulejo foi substituído, assim mostrando a substituição. $O$ banheiro da sala de espera o piso é de azulejo bordô e também está faltando alguns com o contrapiso aparente. Na laje da sala de espera uma parte está sem reboco com a ferragem e o concreto aparente.

Na plataforma, a cobertura está com infiltrações, mofada, principalmente nas juntas de dilatação, as paredes externas da plataforma estão pichadas e com vidro das janelas quebrado.

O galpão ao lado da estação está com as paredes pintadas e chamuscadas pelo o seu uso, e com os vidros de algumas janelas quebrados.

\section{CONCLUSÃO}

A estrada de ferro sorocabana atingiu a região de Presidente Epitácio-SP por volta de 1920, através de um alongamento construído por interesse políticos. A construção da estação foi um marco principalmente para a cidade na década de 1940, trazendo progresso para a região, simbolizando a chegada do desenvolvimento com a consolidação da ferrovia sorocabana, mas também uma conquista para os cidadãos, escoando produtos e transportando passageiros, civilizando uma região até então inexplorada. Mesmo estando em constante deterioração pelo estado de abandono e sem passar por nenhuma reforma o edifício ainda hoje é referência, sendo um dos poucos edifícios de estilo art déco na cidade, retratando o que havia de mais moderno na época e por sua monumentalidade, mas também por seu valor histórico e cultural para a cidade de 
Santo Anastácio, levando em conta que a formação da cidade e da região se deu progressivamente com a chegada da estrada de ferro, o edifício então tendo todo um envolvimento com o passado histórico e acontecimentos relacionados à formação da cidade atual. Tornando-se um símbolo histórico do período, o qual deveria ser resaltado e lembrado dessa forma, em especial pelos habitantes do município.

\section{REFERÊNCIAS}

GLANCEY, Jonathan, A História da Arquitetura, 1ำ edição, Editora Loyola, São Paulo, 2000.

LEMOS, Carlos A.C., O que é Patrimônio Histórico, 5o edição, Editora Brasiliense, São Paulo, 2000.

JUNIOR, Celso Jaloto Avila, Santo Anastácio, Historia de uma Cidade, 1ํedição, Evangraf, Rio Grande do Sul, 1995.

PREFEITURA MUNICIPAL DE SANTO ANASTACIO. Disponível em <http://www.santoanastacio.sp.gov.br> Acesso em 09 de agosto de 2014. 